number of errors, but it is of little value to those who have read them in a dozen other books. No sources are given, and no references (apart from direct quotations), despite the fact that the book is essentially a compilation of already published data.

KAI CURRY-LINDAHL

Handbook of the Birds of Europe, the Middle East and North Africa: the Birds of the Western Palaearctic. Vol. II Hawks to Bustards. Chief Editor: Stanley Cramp. Oxford UP, £30.

This second volume of the European birdwatcher's bible maintains the very high standards set by the first. It covers three important groups: diurnal birds of prey or raptors, gamebirds, and the curiously diverse assemblage in the order Gruiformes, cranes, bustards, rails and the Andalusian hemipode or little button-quail. If the interval between Volumes I and II (three years) is to become the norm, Volume VII will appear in 1995. But then we are still awaiting Volume XI of Peters' Birds of the World, started in the early 1930 s.

There are two changes in the editorial board, D.I.M. Wallace coming in to do field characters in place of James Ferguson-Lees and C.S. Roselaar to aid Jan Wattel with plumages and suchlike, and the artists are reduced to three: C.J.F. Coombs and Peter Hayman from the original team, and Ian Willis as a newcomer. But the artists are still not acknowledged on the title page; mention on the dust jacket and an inconspicuous note embedded in the introduction are not adequate. Both colour plates and line drawings are all excellent for their purpose. In a context like this, a certain amount of stylisation is essential, but very often the 'iizz' is there too.

The text, as before, is arranged in 16 sections under each species: field characters, habitat, distribution, population, movements, food, social pattern and behaviour, voice, breeding, plumages, bare parts, moults, measurements, weights, structure and geographical variation. Doubtless it would be possible to include more, but this would have threatened the entire enterprise. As it is, the task of editing each volume, and melding together the contributions of twelve contributors into a coherent whole, appears to reach the limits of what is humanly possible within a finite time. All praise therefore to those who are achieving this titanic feat.

RICHARD FITTER

\title{
The Year of the Greylag Goose, by Konrad Lorenz. Eyre Methuen, £9.95.
}

Konrad Lorenz, born in 1903 and now the doyen of behavourists, retired in 1973 from the directorship of the Max Planck Institute for Behavioural Physiology in Bavaria to live in the Alm valley of his native Austria. Here in the fairytale beauty of a valley almost unscathed by man, with woodlands and waters shadowed by rugged mountains, a series of ponds was constructed so that Lorenz could continue to study his beloved geese. Hand-reared geese brought from Bavaria formed the basis of a colony which now remains in the valley throughout the year. The book charts, in text and pictures, the annual cycle of the fascinating and noble species.

Greylag geese are particularly interesting for their familial behaviour, which is in many ways analogous to human family life. The analogy is not anthropomorphic, but based on objective observations. For instance, in pair formation these follow a markedly similar course to that undertaken by humans. A young male will show a sudden infatuation for a particular female, and intense courtship will follow sometimes with much interference from the angry father. The young gander shows off his strength and courage, and if the female responds there is a subsequent partnership ceremony (triumph-calling ceremony). If nothing intervenes the two geese remain faithful to each other for the rest of their lives; as with humans something often does intervene. Analogies are dangerously misleading if taken too far, but, as Lorenz points out in his foreword, this is not sufficient justification for dismissing behavioural 